\title{
Implementation of Cop21: A Model Example with Solar Plants
}

\author{
Jan-Erik Lane \\ Fellow at the Public Policy Institute, Belgrade \\ *Corresponding Author: Jan-Erik Lane, Fellow at the Public Policy Institute, Belgrade
}

\begin{abstract}
Halting climate change is a global coordination task for international governance where the EU plays a very major role. The enactment of the COP21 Treaty is considered as the chief response to the set of challenges that global warming presents to mankind in this century. What more exactly is involved the implementation of the goal of temperature rise at 1,5-2 degrees Celsius?
\end{abstract}

Keywords: Decarbonisation, renewables, global warming risks, Schneider, Stern and Kaya.

\section{INTRODUCTION}

While the global political community debates about the US defection from the COP21 Treaty, things are moving on in real life. The optimists about climate change argue that the objectives of COP21 are still within reach, the pessimists point out that the $\mathrm{CO} 2$ in the atmosphere keeps augmenting. We are now at 405 ppm on the Keeling curve.

The optimists underline the many micro changes the recent years in energy production, efficiency and transformation. However, the pessimists emphasize that the macro picture remains much the same, globally speaking: more of air and sea transportation, coal replaced by oil and gas, the shale gas revolution, constantly more cars and bigger engines, wood coal and deforestation, reduction of Amazons and Borneo forests, etc. Why have the recognition of climate change and its enormous dangers to mankind been so late and so contested by some groups?

\section{THEORY OF GLOBAL WARMING}

The first anticipation of the global warming mechanism was done by Frenchman J. Fourier in the early 19th century, but the theory was developed by Swedish chemist Arrhenius around 1895 . He calculated that a doubling of $\mathrm{CO} 2 \mathrm{ppm}$ would be conducive to a 5 degree increase in global average temperature, which is not too far off the worst case scenario for the 21 rst century, according to UN expertise now.

Yet, it was not until Stephen Schneider published Global Warming in 1989 that the theory started to receive wide attention, no doubt strengthened by the work of Keeling in measuring $\mathrm{CO} 2 \mathrm{ppm}$ globally. Moreover, techniques for viewing the $\mathrm{CO} 2$ layer were developed, increasing the attention to climate change.

Now, the UN reacted with creating a few bodies to look into the changes going on, one of which was the COP framework. The economists jumped in besides the natural scientists, worried about the future costs of this transformation of the atmosphere. On the one hand, Kaya and associates presented in 1997 a model that explained CO2:s with energy and energy intensity of GDP. On the other hand, Stern called global warming the largest externality in human history, calling for international governance in order to stem the growth of greenhouse gases. Stern outlined in 2007 a number of activities aimed at reducing $\mathrm{CO} 2$ emissions, promising also a Super Fund to channel money from rich advanced nations to poor countries and developing economies. As little has been done through the UN system of meetings and agencies - transaction costs - up to date, Stern 2015 asked: "What are we waiting for?"

All theories need confirmation. When the polar ice mountains began to collapse, it seemed decisive evidence for the global warming theory. Other important test implications like glacier retreats everywhere, ocean warming and acidification as well as desertification in Africa also gave support for global warming theory. Denials of climate change appear more and more unfounded, although it is true that more of $\mathrm{CO} 2$ may benefit some fauna or environment niches. 


\section{RISKS FROM ANTHROPOGENIC CLIMATE CHANGE}

Considering the probable damages from global warming, it is astonishing that global warming theory has not been better recognized or even conceptually developed or empirically corroborated. If global warming continues unrestrained, much of Asia will be negatively affected, just as Australia is on the verge of losing its coral reefs. There will be sooner or later:

a) Huge land losses along the costs;

b) Too high temperatures for men and women to work outside;

c) Food production decline;

d) Fish harvest decrease;

e) Droughts and starvation;

f) Lack of fresh water supply;

g) Drying up of rivers, affecting electricity supply;

h) Ocean acidification and species extinction;

i) Highly volatile climate with tremendous damages.

This list is far from complete or exhaustive. One could even mention worse outcomes, like the transformations of warm and cold currents in the oceans. What one may underline is that so far no known negative feedback has been found that could stem global warming naturally. We seem to have mainly only positive feedbacks, meaning outcomes reinforce each other in the same direction. The situation in the Amazons and Borneo is basically "lost", and Siberian forests threatened.

\section{ENERGY-ENVIRONMENT CONUNDRUM}

All forms of energy be measured, and these measures are translatable into each other - a major scientific achievement. One may employ some standard sources on energy consumption and what is immediately obvious is the huge numbers involved - see Table 1 .

Table1. Energy consumption 2015 (Million Tons of oil equivalent)

\begin{tabular}{|l|l|l|}
\hline & Total & $\%$ \\
\hline Fossil fuels & 11306,4 & 86,0 \\
\hline Oil & 4331,3 & 32,9 \\
\hline Natural Gas & 3135,2 & 23,8 \\
\hline Coal & 3839,9 & 29,2 \\
\hline Renewables & 1257,8 & 9,6 \\
\hline Hydroelectric & 892,9 & 6,8 \\
\hline Others & 364,9 & 2,8 \\
\hline Nuclear power & 583,1 & 4,4 \\
\hline Total & 13147,3 & 100,0 \\
\hline
\end{tabular}

Source: BP Statistical Review of World Energy 2016

Basically, roughly 90 per cent of all energy consumption comes from non-renewables. The COP21 call for decarbonisation involves a sharp reduction of fossil fuels up until 2030 in order to stabilize climate change with a 30-40 decrease in $\mathrm{CO} 2$ emissions.

\section{ENERGY, EMISSIONS AND THE SUSTAINABILITY MYTH}

The Kaya model correctly emphasizes the links between $\mathrm{CO} 2$ :s, energy consumption of fossil fuels and the energy intensity of GDP (Appendix I). Applying this model onto most available data gives us two key Figures.

First, we see that $\mathrm{CO} 2$ emissions are closely connected with energy consumption, globally speaking. And the projections for energy augmentation in the $21^{\text {st }}$ century are enormous (EIA, BP, IEA). 


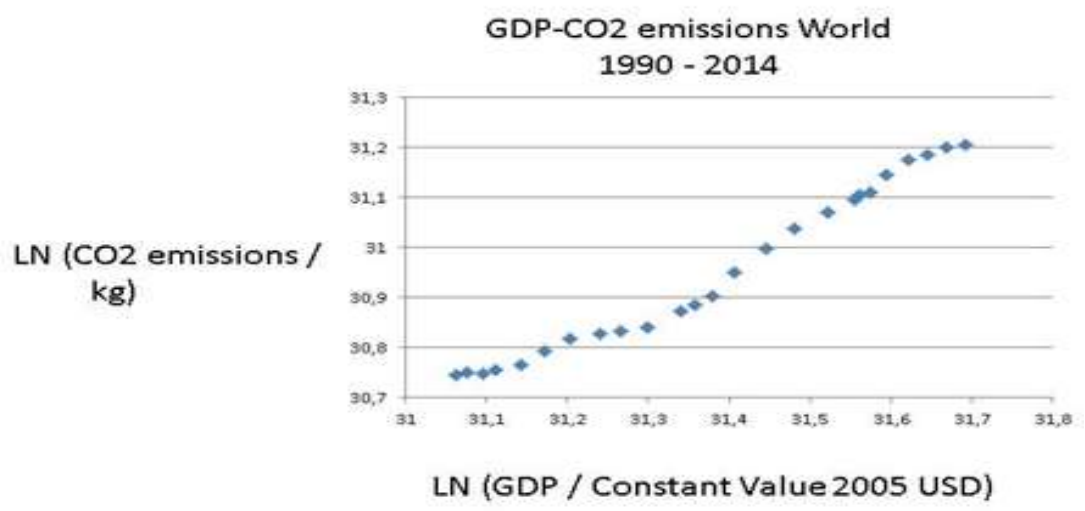

Figure1. Global GDP-CO2 link: $y=0,80 x+5,96 ; R^{2}=0,97(N=59)$

The findings show that total GHG:s or CO2:s go with larger total GDP, i.e. GDP per person * population. Decarbonisation is the policy promise to undo these inks by making GDP and energy consumption rely upon carbon neutral energy resources, like modern renewables and atomic energy. Thus, the upward sloping curves must be reversed but still slope outward.

As, total energy consumed rises, so CO2:s increase. Secondly, energy means power and consequently affluence and wealth. It is hotly desired by men and women in today's world, as Figure 2 entails.
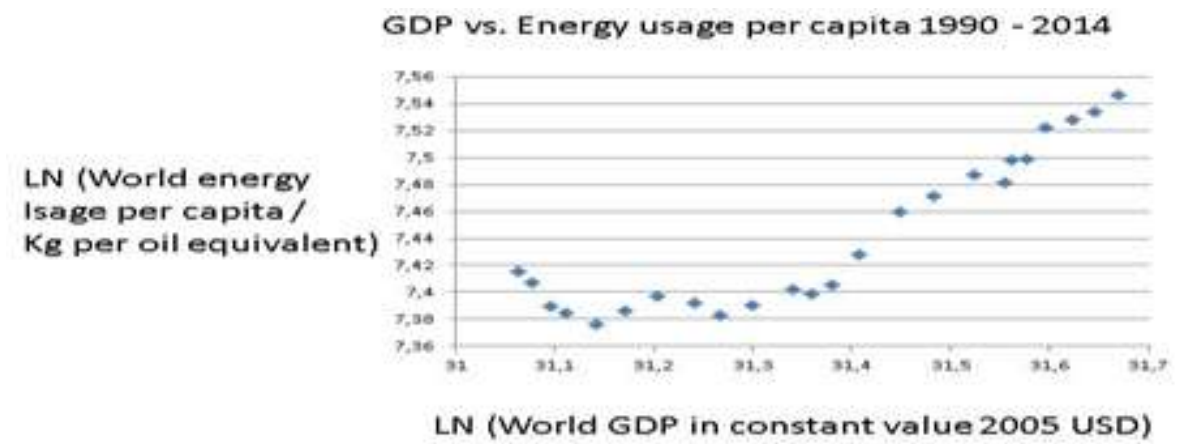

Figure2. Energy consumption per capita globally

With such a demand for energy, resulting in sharply rising $\mathrm{CO} 2$ :s per capita, how is mankind to avoid the horrendous consequences of climate change? One solution is the vast economic depression with strong cut backs in energy consumption, but no governments will deliberately chose this alternative, as it entails mass poverty and starvation deaths. What international governance in the UNFCCC project aims at together with global state coordination is to engage in decarbonisation while securing economic development. The COP21 objectives are:

a) Halt CO2 increases by 2018-2020; some countries already have done so, but far from all;

b) Reduce $\mathrm{CO} 2$ emissions by 30-40 per cent, depending on how counts, by 2030 - an immense challenge;

c) Complete decarbonisation by 2070-75 - an impossible goal to realize;

J. Sachs (2015) has suggested one way forward, namely the sustainable economy. It is a utopian proposal, mixing climate change with poverty reduction and energy durability. It employs the new catch phrase "sustainability", bit is just talk and morals. One cannot use the global warming crisis to solve other problems, like global redistribution and lack of planning as well as economic predictability. The more of a variety of issues one enters into the global warming equation, the more one receives of confusion and transaction costs, which are already substantial with the UNFCCC mechanism.

No government in the advanced capitalist world will, realistically speaking, accept much of global redistribution, whatever the reasons. And a plan for the global economy lies beyond human intelligence, for computational reasons. The tangible issue is not what policy tools will reduce the burning of fossil fuels, the sooner the better! 


\section{Co2 Emissions And TePerature Change}

One may attempt to calculate exactly how increases in greenhouse gases impact upon temperature augmentations. Take the case of $\mathrm{CO} 2 \mathrm{~s}$, where a most complicated mathematical formula is employed:

1. $T=T c+T n$, where $\mathrm{T}$ is temperature, $\mathrm{Tc}$ is the cumulative net contribution to temperature from $\mathrm{CO} 2$ and $\mathrm{Tn}$ the normal temperature;

But when it comes to methane, it is not known whether the tundra will melt and release enormous amounts. But methane does not stay in the atmosphere long, like CO2s. For the other greenhouse gases, there is no similar calculation as for the CO2s: If humans could eat less meat from cows, it would mean a great improvement, as more than a billion cows emit methane. Food from chicken should replace beef meat and burgers. The general formula reads:

2. $d T=\lambda^{*} d F$, where ' $d T$ ' is the change in the Earth's average surface temperature, ' $\lambda$ ' is the climate sensitivity, usually with degrees Celsius per Watts per square meter $\left({ }^{\circ} \mathrm{C} /[\mathrm{W} / \mathrm{m} 2]\right)$, and ' $d F^{\prime}$ ' is the radiative forcing.

To get the calculations going, we start from lambda between 0.54 and 1.2, but let's take the average $=$ 0.87. Thus, we have the formula (Myhre el al, 1998):

Formula: $0.87 \times 5.35 \times \ln (\mathrm{C} / 280)$.

Figure1. Shows how $\mathrm{CO} 2$ emissions may raise temperature to 4-5 degrees, which would be Hawking's worst case scenario.

\section{CO2 atmospheric concentration vs. Rise in global temperature}

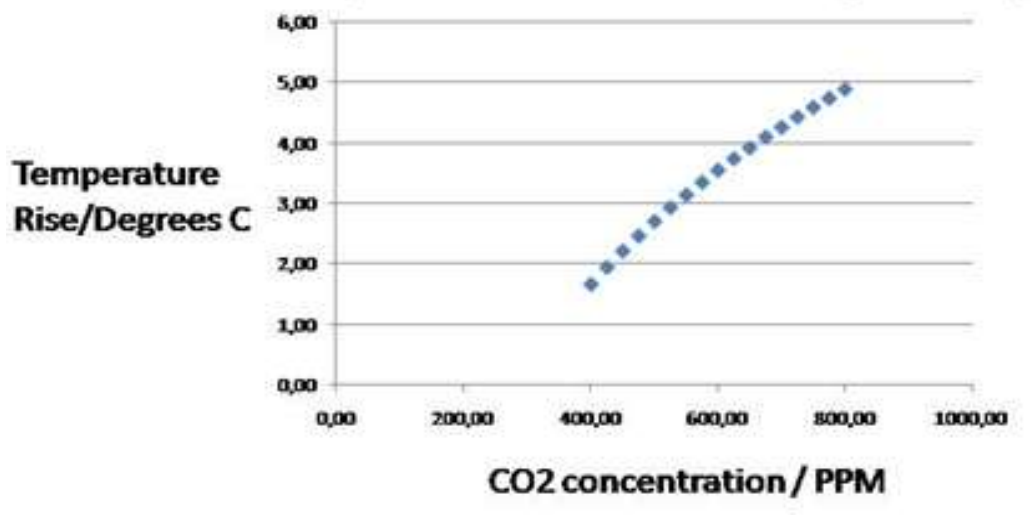

Figure3. $C O 2 s$ and temperature rise in CELCIUS

No one knows where the critical temperature rise occurs, i.e. from which Celsius degree global warming becomes "irreversible", to use Stephen Hawking's expression. It could be as low as +2 Celsius or as high as +5 Celsius.

There are several greenhouse gases, but the two biggest are the CO2s and methane. The UNFCCC has concentrated upon halting and reducing carbon dioxide, but now we are about to face a methane threat. Table 3 shows that methane is growing faster than $\mathrm{CO} 2$.

Table2. GHC minus $\mathrm{CO} 2 \mathrm{~s}$

Year GHG other than $\mathrm{CO} 2$ /Tton

\begin{tabular}{|l|l|}
\hline 1990 & 15,56 \\
\hline 1995 & 15,20 \\
\hline 2000 & 14,74 \\
\hline 2005 & 17,20 \\
\hline 2010 & 17,05 \\
\hline 2011 & 18,47 \\
\hline 2012 & 18,97 \\
\hline
\end{tabular}

Source: EDGARv4.2FT2012, European Commission, Joint Research Centre (JRC)/PBL Netherlands Environmental Assessment Agency. Emission Database for Global Atmospheric Research (EDGAR), release version 4.2 
Figure 3 displays the explosive increase in methane emissions, the consequenecs of which are far from fully known.

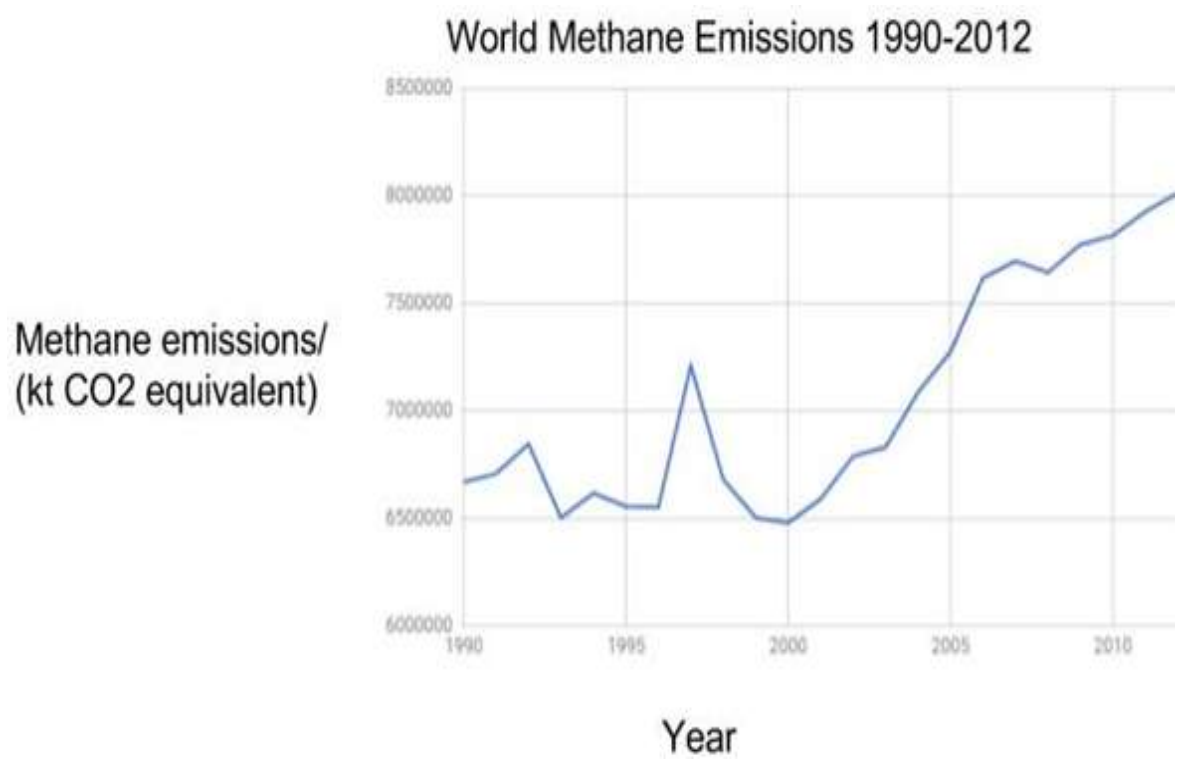

Figure4. Methane emissions

Source: World Bank Data Indicators

The threat from global warming due to methane must be taken most seriously, as methane may be released by the now accelerating melting of the permafrost. The UNFCCC must start paying more attention to other GHGs than only the CO2s.

\section{Cop21: Promise OF DECARbURIZATION}

Let us first focus upon what this hoped for reduction of fossil fuels implies for the augmentation of renewable energy consumption, here solar power. The use of atomic power is highly contested, some countries closing reactors while others construct new and hopefully safer ones. I here bypass wind power and thermal power for the sake of simplicity in calculations. Consider now Table 2, using the giant solar power station in Morocco as the benchmark - How many would be needed to replace the energy cut in fossil fuels and maintain the same energy amount, for a few selected countries with big $\mathrm{CO} 2$ emissions?

Table3. Number of Ouarzazate plants necessary in 2030

\begin{tabular}{|l|l|l|l|}
\hline Nation & $\begin{array}{l}\text { Co2 reduction pledge } \\
\text { \% of } 2005 \text { emissions }\end{array}$ & $\begin{array}{l}\text { Number of gigantic } \\
\text { solar plants needed } \\
\text { (Ouarzazate) }\end{array}$ & $\begin{array}{l}\text { Gigantic plants needed } \\
\text { for 40 \% reduction }\end{array}$ \\
\hline United States & $26-28^{1}$ & 2170 & 3100 \\
\hline China & none $^{2}$ & 0 & 3300 \\
\hline EU28 & $41-42$ & 2300 & 2200 \\
\hline India & none $^{2}$ & 0 & 1700 \\
\hline Japan & 26 & 460 & 700 \\
\hline Brazil & 37 & 170 & 190 \\
\hline Indonesia & 29 & 120 & 170 \\
\hline Canada & 230 & 300 \\
\hline Mexico & 30 & 120 & 190 \\
\hline Australia & 25 & 130 & 190 \\
\hline World & $26-28$ & N/A & 16200 \\
\hline
\end{tabular}

\footnotetext{
${ }^{1}$ America pulled out from the deal in June 2017

${ }^{2}$ China and India has only made pledges in terms of CO2 emissions per GDP, not absolute targets

${ }^{3}$ Unclear sum of all countries pledges, several nations have interval in their commitments
} 
Note: Average of 250 - 300 days of sunshine used for all entries except Australia, Indonesia, and Mexico, where 300 - 350 was used. Sources: Paris 2015: Tracking country climate pledges. Carbon Brief, https://www.carbonbrief.org/paris-2015-tracking-country-climate-pledges; EDGAR v 4.3.2, European Commission, Joint Research Centre (JRC)/PBL Netherlands Environmental Assessment Agency. Emission Database for Global Atmospheric Research (EDGAR), release version 4.3.2. http://edgar.jrc.ec.europe.eu, 2016 forthcoming; CO2 Emission Reduction with Solar http://www. solarmango.com/in/tools/solar-carbon-emission-reduction

\section{COP21: STATE OR MARKET}

The COP21 project suggests decentralised implementation of goals, given the dominance of state sovereignty in Public International Law. But what tools can be conducive to such an enormous transformation, outlined in Table? The COP21 Treaty speaks of a Super Fund with a budget of 100 billion US dollars to assist poor countries and emerging economies. The upcoming COP23 must clarify the technicalities of this Super Fund. Taxes or charges on fossil fuels is an effective means, but will it be accepted by unanimity is the coordination group of so many states? Law or international legislation by means of treaties is another tool, but it is hard to enforce such tools.

\section{CONClusion}

Even if some of the solar power will be generated from solar roof panels on small houses, the task of generating sufficient electricity for maintaining present standards of living is herculean, for the nations above and other countries as well most probably. When taking into account that global planning speak of a 20-30 per cent increase in energy for the coming decades, and then one understands the warning of Schneider: This century may most likely be the greenhouse period of mankind.

\section{REFERENCES}

[1] "Arrhenius, Svante August" in Chambers' Encyclopedia. London: George Newness, 1961, Vol. 1.

[2] Kaya, Y. and Yokoburi, K. (1997) Environment, energy, and economy: Strategies for sustainability. Tokyo: United Nations University Press

[3] Sachs. J. (2015) The Age of Sustainable Development. New York: Columbia University Press.

[4] Stern, N. (2007) The Economics of Climate Change. Oxford: OUP.

[5] Stern, N. (2015) What are we waiting for? Cambridge, MA: MIT Press.

\section{APPENDIX I}

The so-called Kaya model runs as follows:

(E1) Kaya's identity projects future carbon emissions on changes in Population (in billions), economic activity as GDP per capita (in thousands of \$US(1990) / person year), energy intensity in Watt years / dollar, and carbon intensity of energy as Gton C as CO2 per TeraWatt year." (http://climatemodels.uchicago.edu/kaya/kaya.doc.html)

Concerning the equation (E 1), it may seem premature to speak of a law or identity that explains carbon emissions completely, as if the Kaya identity were a deterministic natural law. It will not explain all the variation, as there is bound to be other factors that impact, at least to some extent. Thus, it is more proper to formulate it as a stochastic law-like proposition, where coefficients will be estimate using various data sets, without any assumption about stable universal parameters. Thus, we have this equation format for the Kaya probabilistic law-like proposition, as follows:

(E2) Multiple Regression: $\mathrm{Y}=\mathrm{a}+\mathrm{b} 1 \mathrm{X} 1+\mathrm{b} 2 \mathrm{X} 2+\mathrm{b} 3 \mathrm{X} 3+\ldots+\mathrm{btXt}+\mathrm{u}$

Note: $\mathrm{Y}=$ the variable that you are trying to predict (dependent variable); $\mathrm{X}=$ the variable that you are using to predict $\mathrm{Y}$ (independent variable); $\mathrm{a}=$ the intercept; $\mathrm{b}=$ the slope; $\mathrm{u}=$ the regression residual. Note: http://www.investopedia.com/terms/r/regression.asp\#ixzz4Mg4Eyugw

Thus, using the Kaya model for empirical research on global warming, the following anthropogenic conditions would affect positively carbon emissions: 
(E3) $\mathrm{CO} 2: \mathrm{s}=\mathrm{F}(\mathrm{GDP} /$ capita, Population, Energy intensity, Carbon intensity).

I make an empirical estimation of this probabilistic Kaya model with a longitudinal test for 19902014, i.e. World data 1990 - 2015:

(E4) $\mathrm{Ln} \mathrm{CO} 2=0,62 * \mathrm{LN}$ Population $+1,28 * \mathrm{LN}(\mathrm{GDP} /$ Capita $)+0,96 * \mathrm{LN}($ Energy/GDP $) ; \mathrm{R} 2=.90$.

\section{AUTHOR'S BIOGRAPHY}

Jan-Erik Lane, has been professor with several universities in Europe, Africa and Asia, publishing some 500 pieces. He lives in Geneva and Yangon.

Citation: Jan-Erik, Lane. "Implementation of Cop21: A Model Example with Solar Plants." International Journal of Managerial Studies and Research (IJMSR), vol 5, no. 9, 2017, pp. 5-11. doi:http://dx. doi.org/10.20431/2349-0349.0509002.

Copyright: ( $) 2017$ Authors. This is an open-access article distributed under the terms of the Creative Commons Attribution License, which permits unrestricted use, distribution, and reproduction in any medium, provided the original author and source are credited. 